\title{
Early post-embryonic polyxenidan millipedes from Saxonian amber (Eocene)
}

\author{
joachim T. Haug, Carolin haug, Christian neumann, Andy Sombke \& Marie K. Hörnig
}

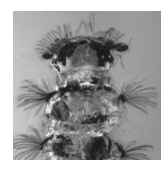

\begin{abstract}
Early post-embryonic stages of arthropods are rarely found in the fossil record. They seem even more rarely reported in literature, possibly as it is more difficult to establish new species based on these specimens. Here we report two immature specimens of polyxenidan myriapods (Diplopoda, Polyxenida) preserved in Saxonian amber (Eocene). Specimen 1 represents a stage I individual with only three pairs of trunk appendages, the collum and three additional tergites. It is interpreted as a representative of the polyxenidan ingroup Polyxenidae. Specimen 2 represents a stage II individual with four pairs of trunk appendages, the collum and three well-sclerotised tergites. It is interpreted as a representative of the polyxenidan ingroup Synxenidae. We additionally discuss the challenges of further systematically interpreting immatures and fossil polyxenidans in general. We also discuss how the further exploration of data of immature polyxenidans, extant and fossil, has the potential to improve our understanding of their evolution and biology. Key words: Myriapoda, Diplopoda, Polyxenidae, Synxenidae, immatures.
\end{abstract}

Haug, J.T., HAug, C., Neumann, C., SOMBKe, A. \& HöRnig, M.K. 2018. Early post-embryonic polyxenidan millipedes from Saxonian amber (Eocene). Bulletin of Geosciences 93(1), 1-11 (4 figures). Czech Geological Survey, Prague. ISSN 1214-1119. Manuscript received November 7, 2016; accepted in revised form January 2, 2018; published online March 20, 2018; issued March 31, 2018.

\begin{abstract}
Joachim T. Haug, \& Carolin Haug, LMU Munich, Biocenter, Department of Biology II and GeoBio-Center, Großhaderner Straße 2, 82152 Planegg-Martinsried, Germany; joachim.haug@palaeo-evo-devo.info, carolin.haug@palaeo-evo-devo.info • Christian Neumann, Museum für Naturkunde Berlin, Leibniz Institute for Evolution and Biodiversity Science, Invalidenstraße 43, 10115 Berlin, Germany; christian.neumann@mfn-berlin.de • Andy Sombke \& Marie K. Hörnig, Ernst-Moritz-Arndt-University of Greifswald, Zoological Institute and Museum, Cytology and Evolutionary Biology, Soldmannstraße 23, 17487 Greifswald, Germany; andy.sombke@uni-greifswald.de, marie.hoernig@palaeo-evo-devo.info
\end{abstract}

As Minelli et al. (2006) have pointed out, modern systematic biology is principally centered on adults. This also applies for fossil species. In comparison to juveniles, new species can be erected more easily based on adult fossil representatives (although it is possible to identify new species on immatures, examples in Haug, C. et al. 2015). Yet, for understanding evolutionary patterns, especially the evolution of development, it is crucial to gain additional information on immature stages from the fossil record (e.g. Nützel et al. 2007; Horner \& Goodwin 2009; Scannella \& Horner 2010; Haug, J. T. \& Haug, C. 2013; Haug, J. T. et al. 2013a, 2016a). Also, fossil developmental stages may inform about now extinct larval morphologies or minimum ages for special larval forms (e.g. Haug, C. \& Haug, J. T. 2016).

In fact, fossils of immatures seem to be more widespread than generally attributed (personal observation JTH), but have not been treated as intensively as adults, despite their importance. Even if we find records of non-adult forms in the literature, later immature developmental stages tend to be more often present in the literature than earlier ones. This may be attributed to the fact that:

(1) later stages tend to be larger and may have a better potential to be preserved, and

(2) later stages may resemble corresponding adults more closely and therefore often may still allow a systematic evaluation.

Notable exceptions to the given discussion are fossils in so-called Orsten-type preservation. This exceptional type of preservation seems to favour smaller specimens and earlier developmental stages in very old sediments. Among the known fossils from Orsten-type Lagerstätten are numerous larval specimens of arthropods, mainly early crustaceans and eucrustaceans (e.g. Haug, J. T. et al. 2009a; recent summary in Haug, C. et al. 2014), but also of cycloneuralian worms (Maas et al. 2007, 2009; Haug, J. T. et al. 2009b; Haug, J. T. \& Haug, C. 2015). While most of these forms could be unequivocally treated systematically 
(due to a lack of possible adult forms), some of them described as species (or "higher" monophyletic taxa) may indeed be larval representatives of species already known from other fossils (e.g. Haug, J. T. \& Haug, C. 2015).

Among Orsten fossils, many very early larval stages are known; some of them most likely represent true first instars. For fossils preserved on slabs, first instars seem to be rare (a possible case of a hatchling of a dictyopteran insect has been described by Hörnig et al. 2014).

Another preservation type with the potential for preserving early post-embryonic immatures is preservation in amber. For some systematic groups (e.g. auchenorrhynchans), immature stages are much more common than adults (Weitschat \& Wichard 2002). Possible hatchlings of jumping bristle tails (Archaeognatha) and cockroaches (Blattodea) have been recently described from Baltic amber (Haug, J. T. et al. 2015, Hörnig et al. 2016). While amber is especially known to preserve insects, other arthropods also occur in amber, and hence potentially their immature stages. Immature myriapods have so far been known from comparably late immature growth stages (e.g. Haug, J. T. et al. 2013b). Here we describe two new fossil specimens of polyxenidan myriapods preserved in Eocene Bitterfeld, i.e. Saxonian, amber. Both specimens are very early developmental stages. The significance of these findings is discussed.

\section{Material \& Methods}

\section{Material}

This study is based on two specimens, both preserved in pieces of Saxonian amber. The specimens are housed in the amber collection of the Museum für Naturkunde Berlin, Germany, under the collection numbers MB.A0538 and MB.A0539. Saxonian amber (also known as "Bitterfeld amber") was derived from the open pit lignite mine "Goitsche" near Bitterfeld, Sachsen-Anhalt, central Germany. The age of Bitterfeld amber is Eocene, and thus same-aged as Baltic amber (e.g. Wolfe et al. 2016). Both studied pieces of amber are of sufficient transparency, nevertheless, not all details of the specimens can be accessed.

\section{Methods}

The specimens were documented with a Zeiss Axiophot compound microscope equipped with a ToupTek DCM 510 ocular camera. Images were taken with $4 \times$ and $10 \times$ objectives, which results in a magnification of 40 and 100 times, respectively. In order to reduce reflections, polarisation filters were applied in front of the light source and camera (cross-polarised light). Glycerin and a cover slip were applied on the amber surface to reduce artefacts caused by convexities and concavities. For generating consistently sharp high-resolution images, several image stacks were taken along the z-axis of every part of the specimen. Single image stacks were subsequently fused with the low-cost software ImageAnalyzer and stitched with the Photomerge function of Adobe Photoshop CS4. Red-cyan anaglyphs were generated based on the image stacks by virtual surface reconstruction with ImageAnalyzer (Haug, J. T. et al. 2013b; Hörnig et al. 2016).

\section{Terminology}

For various arthropod ingroups very different special terminologies have been developed. Yet, for allowing large scale comparisons we should have a set of terms applicable for all arthropods (Simonetta \& Delle Cave 1981). We therefore try to keep the overall description in neutral terminology to allow non-expert readers to follow the text.

It is important to mention, specifically in the case of polyxenidan myriapods, that their dorsal cuticular structures are often termed 'trichomes'. The terminology of arthropod surface structures is far from uniform, and the term 'trichome' implies several distinct aspects of a structure:

(1) The structure is formed only by the epicuticle and exocuticle (e.g. Wehner \& Gehring 2013), different from a true seta where endocuticle is also involved in the formation of the structure. Similar to a trichome in this aspect is a 'spine'.

(2) There is no distinct joint between the structure and the surrounding cuticle. True setae are generally thought to have a distinct joint (e.g. Wehner \& Gehring 2013), although Garm (2004) has applied the term 'seta' in a wider sense also including cuticular structures that are not jointed. Again the trichome is similar in this aspect to a spine.

(3) The first two aspects do not allow differentiation between a trichome and a spine; following the name, a trichome should appear 'hair-like' while the spine is more massive.

Dorsal cuticular structures of polyxenidan myriapods clearly do not at all appear hair-like (see also below). Therefore, the polyxenidan dorsal structures addressed as 'trichomes' may fulfil some of the criteria for identifying a trichome, but not all. To avoid any misunderstandings, i.e. unintended implication of certain characteristics, we make the following compromise: the structures that are usually termed 'trichomes' in polyxenidan myriapods are here referred to as 'setae' in the sense of Garm (2004). (Short side note: 'Seta' is also more compatible to the vernacular name of polyxenidan myriapods, "bristle/bristly millipedes"). 


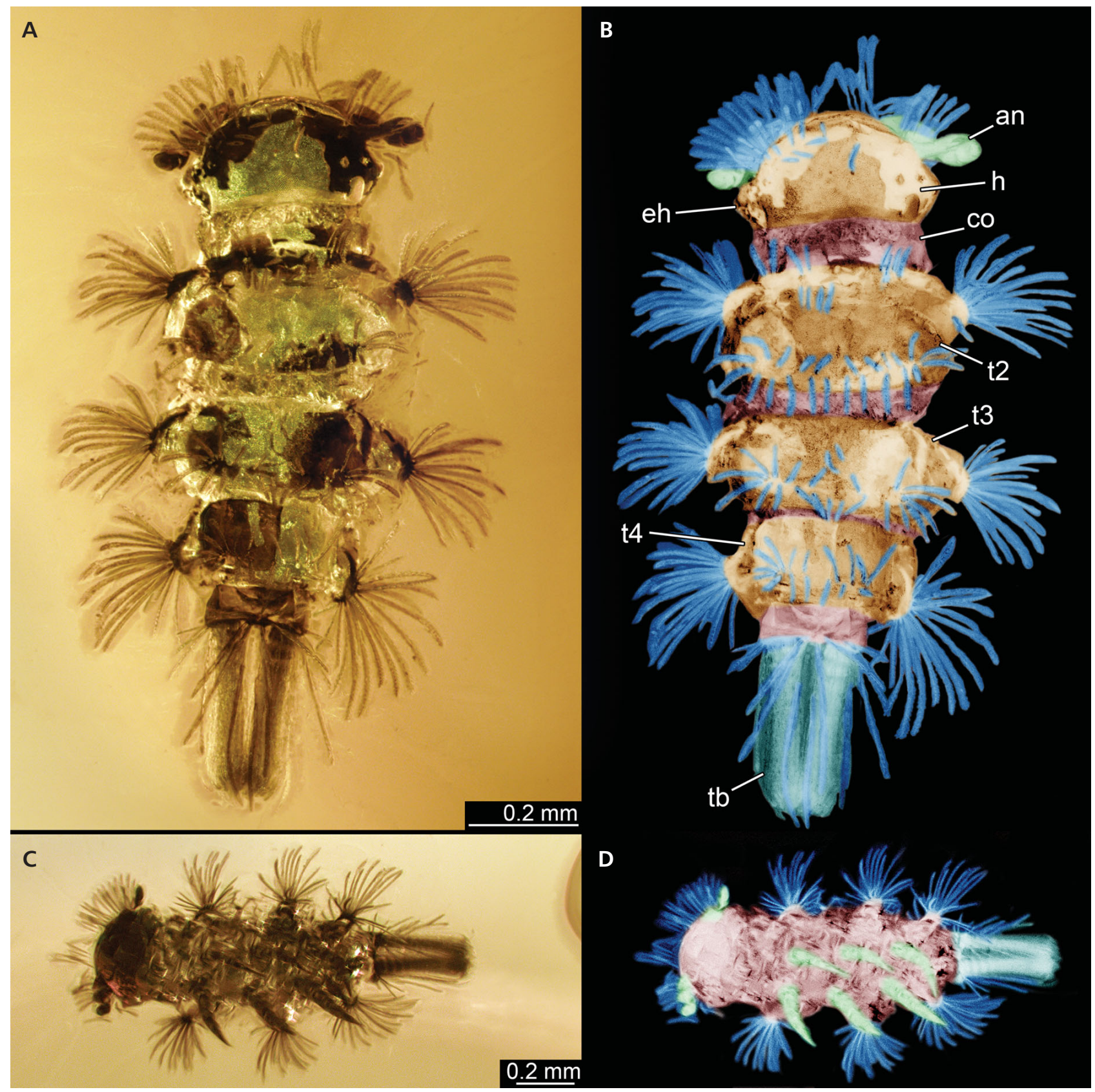

Figure 1. Polyxenidae sp., first instar, specimen 1 MB.A0538, preserved in Saxonian amber; A - dorsal view; B - colour-marked version of A. Head and tergites of appendage-bearing trunk segments in orange, other dorsal areas in red, appendages in green, club-shaped setae in blue, tail brush in cyan; C - ventral view; D - colour-marked version of C. Body in red, appendages in green, club-shaped setae in blue, tail brush in cyan. Abbreviations: an $=$ antenna (antennula); $\mathrm{co}=$ collum; eh $=$ eye hill; $\mathrm{h}=$ head; $\mathrm{t} 2-4=$ tergites of appendage-bearing trunk segments $2-4$; tb $=$ tail brush.

Morphological characters exhibiting incomplete or unclear features have been interpreted on the base of visible details (e.g. presumable eyes). More general terms are added in brackets ('antenna' vs. 'antennula'). We reject ranked classifications. References to traditionally recognised ranked groups are given in brackets for historical reference.

\section{Results}

\section{Description of specimen 1 MB.A0538}

Body organisation. - The body is organised into head and trunk (Figs 1,2). The length of the body is about 1.3 $\mathrm{mm}$ including tail brush (also termed 'caudal bundles'; 


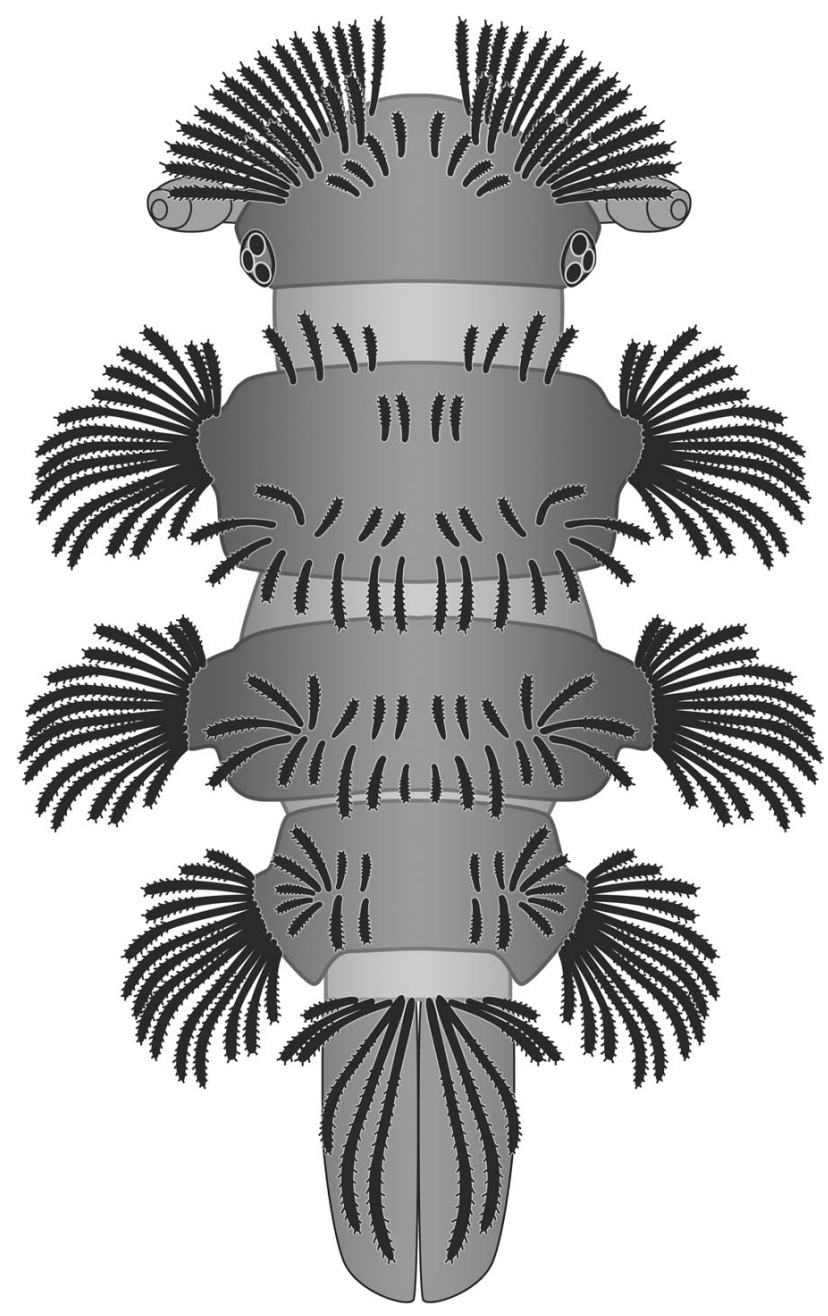

Figure 2. Simplified reconstruction of specimen 1 MB.A0538 in dorsal view.

body length $1 \mathrm{~mm}$ without tail brush) and maximum width is about $0.4 \mathrm{~mm}$. The head dorsally forms a head capsule. In dorsal view, the head capsule has a maximum length of half of maximum width. The anterior rim is gently rounded (in dorsal view) and the posterior rim is straight.

On the postero-lateral corners of the head capsule, there are three small humps bearing smaller cap-like structures (interpreted as lenses of ommatidia sensu Müller et al. 2007) per side. The head capsule bears three rows of setulose setae. The first row along the anterior rim includes about 15 club-like setulose setae on each side of the anterior rim. The second row further medio-posteriorly includes about 5 club-like setulose setae on each side of the body. These setae appear stouter and shorter than the further anterior ones. The third row includes 4 club-like setulose setae further medially. These appear even stouter and shorter than the further anterior ones. Trichobothria are not discernible.
Dorsal trunk organisation. - The trunk is dorsally differentiated into the thin, not well sclerotised collum-bearing area (generally interpreted as the dorsal area of a legless first trunk segment), three prominent leg-bearing segments and the posterior trunk end (telson). The rather unsclerotised appearing area behind the head (collum) lacks setae.

Tergite of trunk segment 2 is well sclerotised. This tergite is slightly larger than the head in anterior-posterior dimensions and slightly wider. The anterior rim of the tergite is slightly convex. The lateral and posterior rims of the tergite are slightly convex, with a distinct protrusion. Laterally it is armed with about 16 club-like setulose setae on each side, arising from the protrusions. The setae are different in size, further anterior and posterior ones are shorter (and stouter) than middle ones. The tergite dorsally is armed with three groups of stouter club-like setulose setae on each side. The first group of four setae is located at the anterior part; the median two setae are stouter than further lateral ones.

The second group of setae is located at about one third along the anterior-posterior axis from the anterior rim and comprises two setae along the lateral-median axis. Both are located far medially; the distance to the group is on the other half of the tergite as large as the distance between the setae of one group. The area behind the tergite (intersegmental membrane) is about half as long (in anterior-posterior dimension) as the collum.

Tergite of trunk segment 3 is well sclerotised. The tergite is slightly shorter but wider than the head in anterior-posterior dimensions. The anterior rim of the tergite is markedly convex.

The lateral rim of the tergite is slightly convex, with a distinct lateral protrusion. The posterior rim of the tergite is slightly concave. The tergite laterally is armed with about 15 club-like setulose setae on each side, arising from the protrusions. The setae are different in size; the further anterior and posterior ones are shorter (and stouter) than middle ones. The tergite dorsally is armed with a single group of stouter club-like setulose setae on each side. The first group of setae in the posterior part is located at the half of the tergite and comprises two rows of 6 setae. The distance to the group on the other half of the tergite is as large as the distance between the setae of one group.

The area behind the tergite (intersegmental membrane) is rather short, less than half of the preceding one and tapering posteriorly.

Tergite of trunk segment 4 is well sclerotised. The tergite is about as long as the preceding tergite, but significantly narrower. The anterior rim of the tergite is slightly convex. The lateral rim of the tergite is latero-posteriorly drawn out into distinct protrusions. The posterior rim of the tergite is concave further laterally and straight medially. The tergite laterally is armed with about 14 club-like setulose setae on each side, arising from the protrusions. The 
setae are different in size; the further anterior and posterior ones are shorter (and stouter) than middle ones. The tergite dorsally is armed with a single group of stouter club-like setulose setae on each side. The first group of setae in the posterior part is located at the half of the tergite. This group contains two rows with 5 setae in the anterior and 4 in the posterior part. The distance to the group on the other half of the tergite is significantly larger than distance between the setae of one group.

The area behind the tergite of trunk segment 4 (posterior trunk end) appears soft, rather short and is significantly narrower than the preceding tergite (telson). Two prominent structures arise posteriorly from it (tail brushes, caudal bundles). Dorsally six club-like setulose setae on each side (= fan of dorso-medial setae). The setae are differentiated in size and the further lateral ones are shorter (and stouter) than middle ones.

Appendages. - Head appendages besides the antenna (antennula) are not accessible. At least three distal elements of the antenna are apparent. No further details are accessible due to preservation. Mouthparts are not discernible. All three pairs of trunk appendages are elongate conical and about the same size; further details are not accessible due to preservation. No further appendages or anlagen are visible.

\section{Description of specimen 2 MB.A0539}

Body organisation. - The body is organised into head and trunk (Figs 3,4). The length of the body is about $1.6 \mathrm{~mm}$ and maximum width is about $0.6 \mathrm{~mm}$ without appendages. The head dorsally forms a head capsule.

The head capsule in dorsal view has a maximum width which is about 1.8 times longer than the maximum length. The anterior rim is formed convex in shape. The posterior rim is slightly concave, but exhibits a small triangular rounded protrusion medially.

The postero-lateral corners of the head capsule possess nine small humps bearing smaller cap-like structures (interpreted as lenses of ommatidia) per side. There are about 21 elongate setulose setae on each side of the anterior rim of the head as well as two humps on each side of the posterior rim. Trichobothria are not discernible.

Dorsal trunk organisation. - The trunk is dorsally differentiated into a thin collum-bearing segment, three prominent tergite-bearing segments, and the posterior trunk end (telson). The area behind the head (tergite of trunk segment 1 ; collum) is not well sclerotised and equipped with about twelve thin setulose setae on each side of the body.

Tergite of trunk segment 2 is well sclerotised. The tergite is slightly larger than the head in anterior-posterior dimensions and slightly wider. The anterior rim of the tergite is markedly convex in shape. The lateral rim of the tergite is slightly convex, tapering medially towards the posterior rim. The posterior rim of the tergite medially is concave. The tergite is laterally armed with about six elongate stronger setulose setae on each side, arising from along the rim. The tergite is dorsally armed with two groups of elongate thin setulose setae on each side. The first group of setae is located at about one quarter along the anterior-posterior axis from the anterior rim and contains four setae along the latero-median axis. The most median one is located at about one-quarter along the latero-median axis from the lateral rim. The second group of setae is located at about two thirds along the anterior-posterior axis from the anterior rim ("pleural processes"?). The second group contains two rows of four setae, (each) along the lateral-median axis. The most median one is located at about one-quarter along the latero-median axis from the lateral rim.

The area behind the tergite (intersegmental membrane) is about half as long (in anterior-posterior dimension) as the collum.

Tergite of trunk segment 3 is well sclerotised. The tergite is slightly longer than the preceding tergite in anterior-posterior dimension and about as wide. The anterior rim of the tergite is convex laterally and straight medially. The lateral rim of the tergite is almost straight and slightly widening posteriorly. The posterior rim of the tergite is strongly convex and gently rounded. The tergite laterally is armed with about six elongate stronger setulose setae on each side, arising from along the rim. The tergite dorsally is armed with two groups of elongate thin setulose setae on each side. The first group of setae is located at about one third along the anterior-posterior axis from the anterior rim and equipped with four setae along the latero-median axis close to each other. The most median one is located at about one-quarter along the latero-median axis from the lateral rim. An additional single seta is located further medially with a larger distance to the other ones. The second group of setae is located at about two thirds along the antero-posterior axis from the anterior rim; with two rows of four setae (each) along the lateral-median axis ("pleural processes"?). The most median one is located at about one-quarter along the lateral-median axis from the lateral rim.

The area behind the tergite (intersegmental membrane) is longer (in anterior-posterior dimensions) than the preceding one and medially covered by the succeeding tergite.

Tergite of trunk segment 4 is well sclerotised. The tergite is shorter than the preceding tergite and slightly narrower. The anterior rim of the tergite is slightly convex and medially drawn out anteriorly. This protrusion is partly concealed by the preceding tergite. The lateral rim of the tergite is more or less straight with rounded corners. The posterior rim of the tergite is more or less straight. The tergite laterally is armed with about six elongate stronger 
setulose setae on each side, arising from along the rim. The tergite is medio-dorsally armed with two groups of elongate thin setulose setae on each side. The first group of setae is located at about one third along the anterior-posterior axis from the anterior rim and equipped with four setae along latero-median axis close to each other. The most median one is located at about one-quarter along the latero-median axis from the lateral rim. An additional single seta is located further medially with a larger distance to the other ones. The second group of setae is located at about two thirds along the anterior-posterior axis from the anterior rim; with 2 rows of 4 setae (each) along latero-median axis ("pleural processes"?). The most median one is located at about one-quarter along the latero-median axis from the lateral rim.

The area behind the tergite (undifferentiated posterior trunk end; growth zone + telson) dorsally appears sclerotised. Anteriorly, it is slightly narrower than the preceding tergite, is strongly tapering terminally, and gently rounded at the terminal end. Tergite of trunk segment 5 seems not yet set off from this area; at least such a differentiation is not possible

A first group of setae is located at about one half along the anterior-posterior axis from the anterior rim and contains four setae along lateral-median axis ("pleural processes"). The most median one is located at about one-quarter along the lateral-median axis from the lateral rim. A second group of setae contains three rows of about three setae each and is located close to the terminal end.

Appendages. - Head appendages are not accessible due to preservation. The antennae (antennulae) are identifiable, but without details. Mouthparts are not discernible. The first pair of trunk appendages is elongate conical, but further details are not accessible due to preservation. The second pair of trunk appendages is elongate conical and larger than preceding appendages, but further details are not accessible due to preservation. The third pair of trunk appendages is elongate conical and about as large as preceding pair of appendages. Further details are not accessible due to preservation. Appendages of the undifferentiated trunk end (growth zone + telson) are elongate-conical and slightly smaller than preceding appendages. Further details are not accessible due to preservation.

\section{Discussion}

\section{General systematic interpretation}

Both specimens described here are interpreted as representatives of the diplopod ingroup Polyxenida, based on overall morphology and especially the presence of numerous prominent setulose setae ("trichomes"). While a similar habitus and armature is also known from certain larval forms of beetles, these differ significantly in overall body organisation (tagmatisation).

The internal systematic of Polyxenida is not well resolved, remaining on a largely phenetic/taxonomic level. In most studies, two sister groups are distinguished: Polyxenoidea and Synxenoidea ("superfamilies"; e.g. Enghoff et al. 2015) with three (Condé \& Nguyen Duy-Jacquemin 2008) or three to four (e.g. Short \& Huynh 2006, Shear 2011, Enghoff et al. 2015) major monophyletic groups ("families"). Yet, the identification of "intermediate forms" (e.g. Nguyen Duy-Jacquemin 2006, Nguyen Duy-Jacquemin et al. 2011) indicates that some of the traditional groups may be non-monophyletic in respects to others.

Representatives of Lophoproctidae lack ommatidia which are present in the here described specimens. The overall habitus of specimen 1 MB.A0538 resembles species of Polyxenidae; that of specimen 2 MB.A0539 resembles species of Synxenidae.

\section{Interpretation of developmental stage}

The further-reaching systematic interpretation is challenging due to the developmental state of the two specimens, and because of their small size morphological details can only be observed to a limited extent.Yet, we can at least identify the developmental states of the specimens.

Specimen 1 MB.A0538 possesses only three trunk tergites behind the collum and only three pairs of walking appendages. Such a state characterises stage I individuals of extant polyxenid and synxenid species. Further developed stages would already bear additional appendages (e.g. Enghoff et al. 1993; Short \& Huynh 2006, 2010). It seems unlikely that additional appendages are already present in the fossil, but are not apparent, as the ventral area is accessible to a large extent. Specimen 1 MB.A0538 therefore is interpreted as a stage I individual.

Specimen 2 MB.A0539 also possesses only three distinct tergites behind the collum, yet here the posterior trunk might indeed already bear further tergites, but these cannot be differentiated from the trunk end due to limitations of preservation in this area. Ventrally four pairs of walking appendages are present. Such a condition characterises stage II individuals in extant species (e.g. Enghoff et al. 1993, Short \& Huynh 2006). Specimen 2 MB.A0539 is therefore interpreted as a stage II individual.

\section{Challenges for finer systematic interpretation}

As both specimens described herein represent very early post-embryonic stages, a finer systematic interpret- 


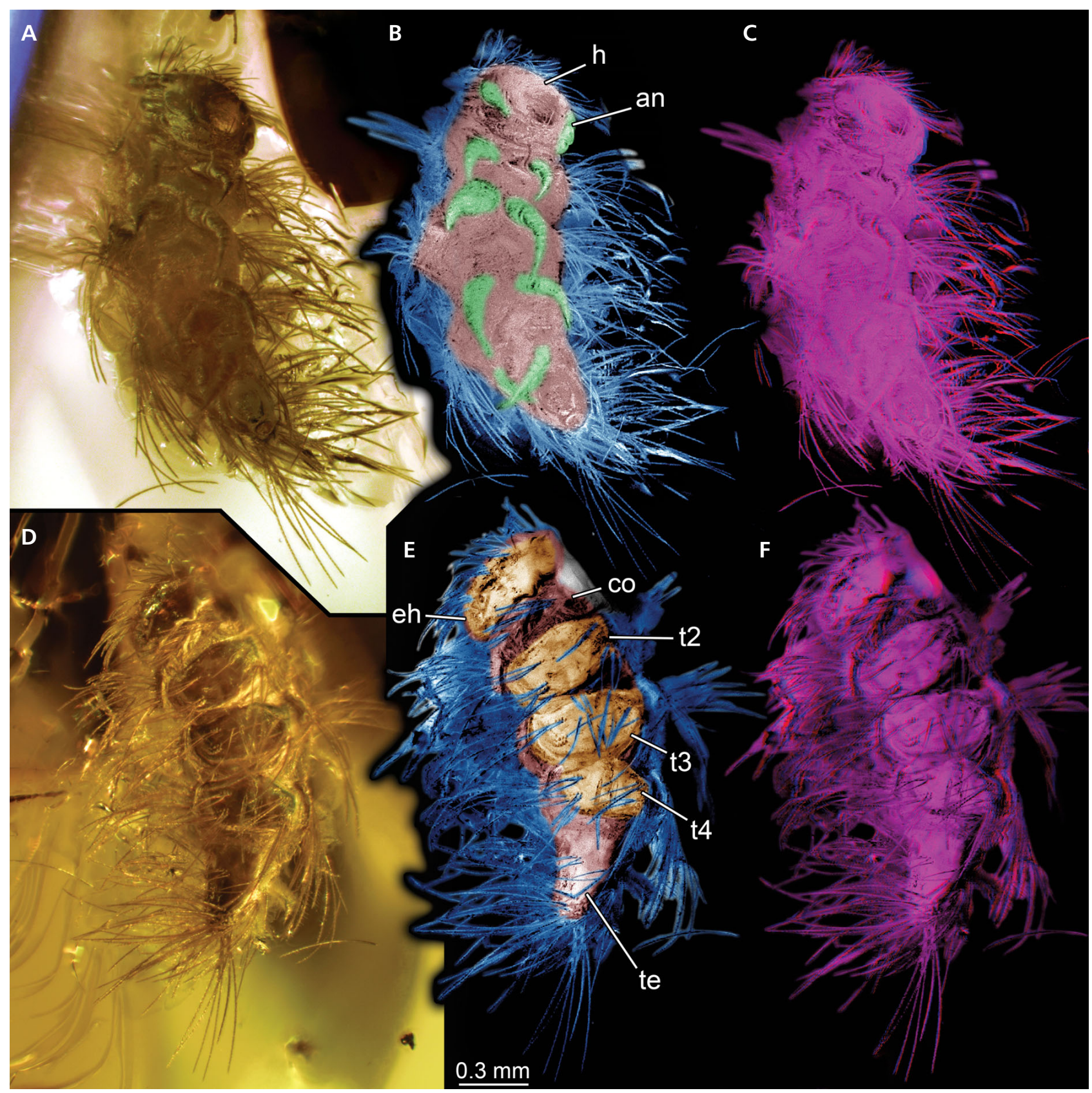

Figure 3. Synxenidae sp., second instar, specimen 2 MB.A0539, preserved in Saxonian amber; A - ventral view; B - colour-marked version of A. Body in red, appendages in green, setae in blue; $\mathrm{C}$ - red-blue stereo anaglyph of a virtual surface reconstruction showing the overall topology; D - dorsal view; $\mathrm{E}$ - colour-marked version of D. Head and tergites of appendage-bearing trunk segments in orange, other dorsal areas in red, setae in blue; F - red-blue stereo anaglyph of a virtual surface reconstruction showing the overall topology. Use red-blue stereo glasses to view $\mathrm{C}$ and $\mathrm{F}$. Abbreviations: an $=$ antenna (antennula); co = collum; eh = eye hill; $\mathrm{h}=$ head; $\mathrm{t} 2-4=$ tergites of appendage-bearing trunk segments $2-4$; te $=$ telson.

ation is challenging. This is caused by the following reasons:

(1) Fossils in general seem to have been largely excluded from comparative approaches with the argument that the fossils would not provide the necessary information (e.g. Short \& Huynh 2006). While this seems to be a general view from the neontological point of view, in- stead it would seem reasonable for establishing additional characters for distinguishing species that might also be accessible in fossils (see argumentation in Hyžný \& Klompmaker 2015).

(2) Due to the early developmental state the examined specimens are quite small. Amber often hampers the access to common "taxonomically important" characters (see e.g. 


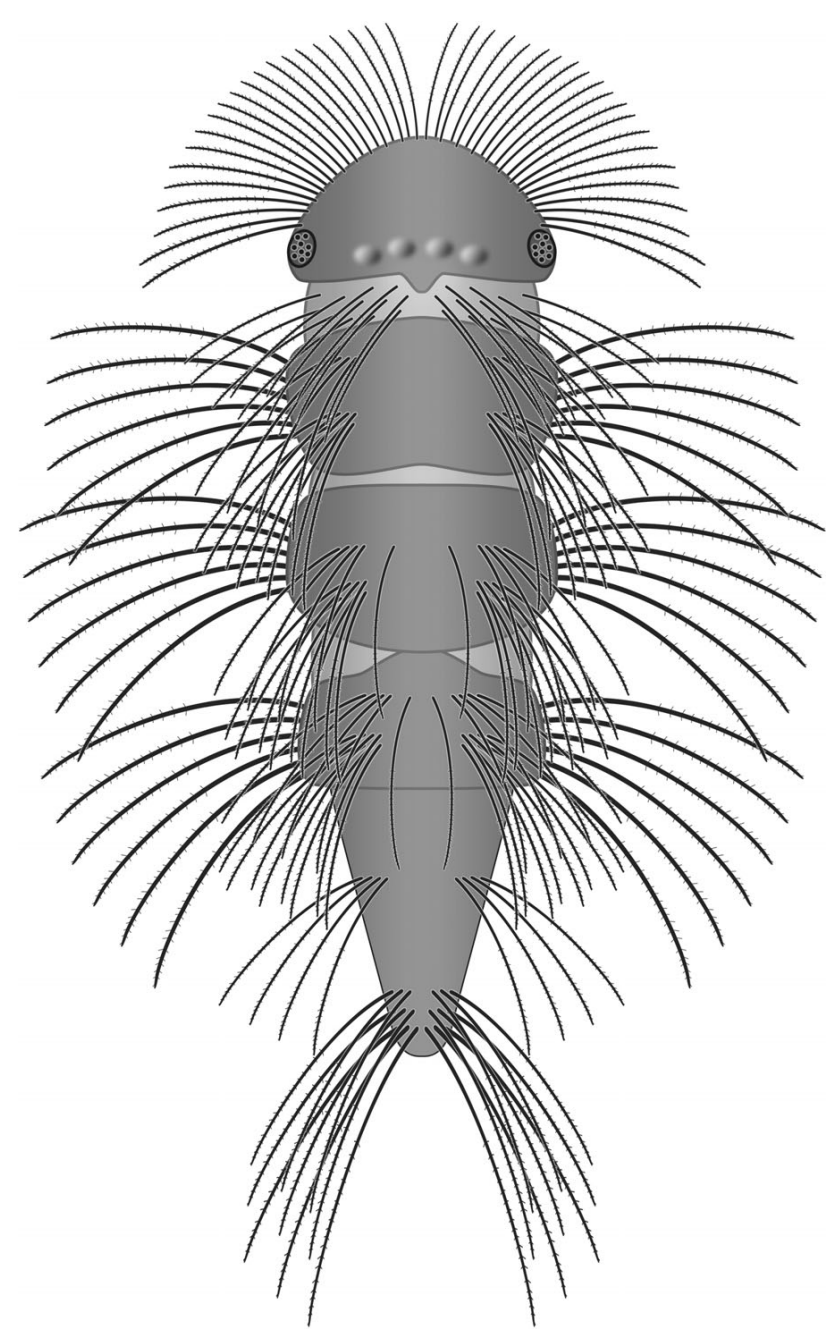

Figure 4. Simplified reconstruction of specimen MB.A0539 in dorsal view.

Hädicke et al. 2013). This is especially the case in smaller specimens (see e.g. discussion in Haug, J. T. et al. 2013b). In addition, structures in the adult stage that are relevant for identification (e.g. gonopods, number of ommatidia, number of antennomeres) are mostly fewer or absent in developmental stages.

(3) Even among extant species delineation appears to be not perfectly developed. Characters used for distinguishing species seem to be difficult to access even in modern species (e.g. Short \& Huynh 2006, 2009).

(4) Immature specimens are especially difficult to interpret in a systematic context even among modern species. Early post-embryonic stages, even if they were mentioned and some aspects discussed, are rarely depicted (e.g. Nguyen Duy-Jacquemin 2006, Short \& Huynh 2006). Even if depicted, the chosen presentation is largely restricted to line drawings (e.g. Enghoff et al. 1993), making a comparison to fossils far from easy.

(5) There continues to be a major misconception of tax- onomy vs. systematics within the community. Systematics is about finding sistergroup relationships. The erection of new ranks is (largely) unrelated to this and a matter of convention. As an example, Nguyen Duy-Jacquemin (2006) and Nguyen Duy-Jacquemin \& Azar (2004) emphasise the fact that newly described species are described in separate genera. Yet, the interpretation of a species to represent a separate genus is an active decision of the researcher and not the representation of a natural characteristic of the species. In other words there is no rule when to erect a new genus. As another example Condexenus biramipalpus (Nguyen Duy-Jacquemin 2006) could as well have been described as a new species of Phryssonotus, possibly representing the sister group to all other species. As a consequence it is difficult to separate phylogenetic information from taxonomic habits, making phylogenetic interpretations more difficult.

\section{Further interpretation of specimen 1 MB.A0538}

As stated further above, the specimen's overall habitus clearly argues for an interpretation of the specimen as a representative of Polyxenidae. Within Polyxenidae, approximately 96 species have been recognised (Enghoff et al. 2015). There have been no attempts to differentiate species in early developmental stages, nor are data available for these stages of all species of the group to allow a differential comparison. Thus, the systematic interpretation for this specimen remains general and reference to it should be made as Polyxenidae sp.

No less than five species of Polyxenidae are known from Baltic amber (Nguyen Duy-Jacquemin \& Azar 2004, Edgecombe 2015), all interpreted as representatives of Polyxenus. All have the potential to be conspecific with the specimen described here; yet, it also could represent a new species. It should be kept in mind that due to the difficulties in comparing fossil and extant forms (e.g. Short \& Huynh 2006) these traditionally recognised five species might turn out to be representatives of other species groups ("genera") than Polyxenus. For potentially linking the here described immatures to a further developed specimen identifiable to species level, we would need more complete developmental series including subadults or adults. Hence more descriptions of immature specimens and a rigorous comparison of these to extant species are warranted.

\section{Further interpretation of specimen 2 MB.A0539}

The group Synxenidae was at first recognised from fossil representatives in amber (e.g. Nguyen Duy-Jacquemin \& 
Azar 2004). The entire group is less species-rich than Polyxenidae including eight extant (Enghoff et al. 2015) and three fossil species, one additional unnamed species from French (Cretaceous) amber, one unnamed species from Burmese amber (Cretaceous) and one unnamed species from Baltic amber (Eocene; e.g. Nguyen Duy-Jacquemin \& Azar 2004, Rasnitsyn \& Golovatch 2004, Short \& Huynh 2006, Shear \& Edgecombe 2010, Edgecombe 2015). While we could argue that given this pattern, the specimen described here should likely be conspecific with the species known from Baltic amber (Phryssonotus hystrix), we cannot exclude that the new specimen represents a new species.

The specimen shows some rather unusual features:

(1) Extant representatives of Synxenidae are characterised by dorsal scale-like setae. These are apparently absent in our specimen. Yet, Nguyen Duy-Jacquemin (2006) described a specimen of the synxenid Condexenus biramipalpus in the corresponding stage having lost the scale-like setae besides a single one. Therefore, it is probable that this is also the case in the specimen described here.

(2) Although roughly preserved, the specimen appears to have a comparably large number of lenses of ommatidia (i.e. nine). Condexenus biramipalpus (Nguyen Duy-Jacquemin 2006) and Phryssonotus novaehollandiae (Short \& Huynh 2006) both possess only five ommatidia in the corresponding stage. The higher number in our specimen may be of importance. For the present, however, this information is not available for all known extant species.

As noted for specimen 1 MB.A0538, more material including subadult and adult specimens will be necessary for establishing a reliable ontogenetic link to more advanced developed or even mature specimens. Also a rigorous comparison to extant ontogenetic sequences will be necessary for a further reaching systematic interpretation. Thus, the systematic interpretation of this specimen remains general and reference to it should be made as Synxenidae sp.

\section{Importance of fossil immatures}

As outlined above, a discrete systematic interpretation of the specimens described here is at least challenging, also leading to rather general questions. One could therefore ask why the investigation of fossil immatures is of scientific value at all. While this discussion has in fact been waged in several instances, we will provide here a short summary of the main reasons for not only discussing adults of fossil species and shortly point out how these relate to the case presented here.

(1) Taxonomy 1: Developmental stages (extant and fossil) have been erroneously identified as separate species in the past (see discussions e.g. in Horner \& Goodwin
2009; Scannella \& Horner 2010; Haug, J. T. et al. 2012; Haug, J. T. \& Haug, C. 2015). This is unlikely to be the case in the specimens examined in this study.

(2) Taxonomy 2: Developmental patterns may be a major factor for delineating species (Haug, C. et al. 2012). The difficulty for such an approach is that establishment of an ontogenetic sequence is necessary first, which remains challenging for most fossil species. As species delineation among polyxenidans is still difficult, ontogenetic characters may indeed be of importance.

(3) Heterochrony: It has been suggested that changes in the developmental pattern have played a role in the evolution of Polyxenida (e.g. Nguyen Duy-Jacquemin et al. 2011). If we want to also involve fossil species into evolutionary reconstructions of heterochronic events, ontogenetic data need to be included (e.g. Haug, J. T. et al. 2010a, b).

(4) Ancestral patterns: As pointed out in the previous points, the reconstruction of ontogenetic patterns may provide important insights into evolutionary pattern, e.g. when certain developmental patterns have been established. We generally assume that fossil representatives of a group develop in similar patterns compared to modern species, yet this does not necessarily have to be the case (e.g. Haug, J.T. et al. 2013a, 2016b; Haug, J. T. \& Haug, C. 2013, 2016). For the present case, we can recognise that tens of million years ago polyxenidans immatures strongly resembled their modern counterparts and already developed in more or less the same developmental pattern as today, as far as we can tell.

(5) Autecological interpretations: Especially the very early post-embryonic stages may be informative about the autecology of a given species, for example for differentiating between feeding and non-feeding early stages (see $e$.g. Haug, J. T. et al. 2009a vs. 2010a; Nützel 2014). In some cases, the morphology of the very early stages may also be informative for possible social interactions (Hörnig et al. 2016). In the present case, the individuals appear to have been actively mobile and not being dependent on interactions with conspecific individuals.

(6) Dem- and synecological interpretations: From a faunistic-ecological point of view it is interesting to recognise whether early developmental stages occur in the same region or habitat as their corresponding adult stages and vice versa. This might reveal possible niche differentiation between the different stages. Currently, overall number of polyxenidans reported from amber is still extremely low. A denser sampling including a clear discussion about the developmental state will be necessary before making clear conclusions in this direction.

Hence we need to summarise that immature fossils have a large potential exploitable in future approaches, yet currently their value remains limited due to the rather small sample size. This also accounts for their extant counter- 
parts for which the clear documentation of early post-embryonic stages needs to be improved.

\section{Acknowledgements}

We thank Isabel Dittmann, Innsbruck, for her help when working in the collections. MKH is kindly funded by the Studienstiftung des Deutschen Volkes. CH was kindly supported by the Bavarian Equal Opportunities Sponsorship (BGF) of the LudwigMaximilians-University Munich. We also thank Steffen Harzsch, Greifswald, and J. Matthias Starck, Munich, for continuous support. We are grateful to all people involved in providing open access, open source and low cost software.

\section{References}

Condé, B. \& Nguyen Duy-Jacquemin, M. 2008. Classification actuelle des Diplopodes Pénicillates (myriapodes) avec nouvelles définitions des taxa. Bulletin de la Société zoologique de France 133, 291-302.

Edgecombe, G.D. 2015. Diplopoda - Fossils, 337-351. In Minelli, A. (ed.) Treatise on Zoology - Anatomy, Taxonomy, Biology. The Myriapoda Volume 2. Brill, Leiden.

Enghoff, H., Dohle, W. \& Blower, J.G. 1993. Anamorphosis in millipeds (Diplopoda) - the present state of knowledge with some developmental and phylogenetic considerations. Zoological Journal of the Linnean Society 109, 103-234. DOI 10.1111/j.1096-3642.1993.tb00305.x

Enghoff, H., Golovatch, S., Short, M., Stoev, P. \& Wesener, T. 2015. Diplopoda - Taxonomic overview, 363-453. In Minelli, A. (ed.) Treatise on Zoology - Anatomy, Taxonomy, Biology. The Myriapoda Volume 2. Brill, Leiden.

GARM, A. 2004. Revising the definition of the crustacean seta and setal classification systems based on examinations of the mouthpart setae of seven species of decapods. Zoological Journal of the Linnean Society 142, 233-252. DOI 10.1111/j.1096-3642.2004.00132.x

Hädicke, C.W., Haug, C. \& Haug, J.T. 2013. Adding to the few: a tomocerid collembolan from Baltic amber. Palaeodiversity 6, 149-156.

Haug, C. \& Haug, J.T. 2016. Developmental Paleontology and Paleo-Evo-Devo, 420-429. In KLIMAN, R.M. (ed.) Encyclopedia of Evolutionary Biology, vol. 1. Academic Press, Oxford.

Haug, C., Haug, J.T., MAAs, A. \& WaloszeK, D. 2014. Fossil larvae (head larvae, nauplii, and others) from the Cambrian in Orsten preservation, 17-26. In Martin, J.W., Olesen, J. \& HøEg, J.T. (eds) Atlas of Crustacean Larvae. The Johns Hopkins University Press, Baltimore.

Haug, C., Van Roy, P., Leipner, A., Funch, P., Rudkin, D.M., Schöllmann, L. \& Haug, J.T. 2012. A holomorph approach to xiphosuran evolution - a case study on the ontogeny of Euproops. Development Genes and Evolution 222, 253-268. DOI 10.1007/s00427-012-0407-7

Haug, C., Wiethase, J.H. \& Haug, J.T. 2015. New records of Mesozoic mantis shrimp larvae and their implications on modern larval traits in stomatopods. Palaeodiversity 8, 121-133.

Haug, J.T. \& Haug, C. 2013. An unusual fossil larva, the ontogeny of achelatan lobsters, and the evolution of metamorph- osis. Bulletin of Geosciences 88, 195-206.

DOI 10.3140/bull.geosci.1374

Haug, J.T. \& Haug, C. 2015. Worm Palaeo-Evo-Devo - The ontogeny of Ottoia prolifica from the Burgess Shale. Research \& Reviews: Journal of Zoological Sciences 3(1), 3-14.

Haug, J.T. \& Haug, C. 2016. "Intermetamorphic" developmental stages in 150 million-year-old achelatan lobsters - The case of the species tenera Oppel, 1862. Arthropod Structure \& Development 45, 108-121. DOI 10.1016/j.asd.2015.10.001

Haug, J.T., Audo, D., Charbonnier, S. \& Haug, C. 2013a. Diversity of developmental patterns in achelate lobsters - today and in the Mesozoic. Development Genes and Evolution 223, 363-373. DOI 10.1007/s00427-013-0452-x

Haug, J.T., Audo, D., Charbonnier, S., Palero, F., Petit, G., Abi SAAD, P. \& HAUG, C. 2016b. The evolution of a key character, or how to evolve a slipper lobster. Arthropod Structure \& Development 45, 97-107. DOI 10.1016/j.asd.2015.08.003

Haug, J.T., Hädicke, C.W., Haug, C., Hörnig, M.K. 2015. A possible hatchling of a jumping bristle tail in 50 million years old amber. Neues Jahrbuch für Geologie und Paläontologie-Abhandlungen, 278(2), 191-199.

DOI 10.1127/njgpa/2015/0523

Haug, J.T., Haug, C. \& Garwood, R. 2016a. Evolution of insect wings and development - new details from Palaeozoic nymphs. Biological Reviews 91, 53-69. DOI 10.1111/brv.12159

Haug, J.T., MaAs, A. \& Waloszek, D. 2009a. Ontogeny of two Cambrian stem crustaceans, †Goticaris longispinosa and $\dagger$ Cambropachycope clarksoni. Palaeontographica A 289, 1-43. DOI 10.1127/pala/289/2009/1

Haug, J.T., MaAs, A. \& Waloszek, D. 2010a. †Henningsmoenicaris scutula, $\uparrow$ Sandtorpia vestrogothiensis gen. et sp. nov. and heterochronic events in early crustacean evolution. Earth and Environmental Science Transactions of the Royal Society of Edinburgh 100, 311-350. DOI 10.1017/S1755691010008145

Haug, J.T., MaAs, A., Waloszek, D., Donoghue, P.C.J. \& Bengtson, S. 2009b. A new species of Markuelia from the Middle Cambrian of Australia. Memoirs of the Association of Australasian Palaeontologists 37, 303-313.

Haug, J.T., Müller, C.H.G. \& Sombke, A. 2013b. A centipede nymph in Baltic amber and a new approach to document amber fossils. Organisms Diversity \& Evolution 13, 425-432. DOI 10.1007/s13127-013-0129-3

Haug, J.T., Waloszek, D., Haug, C. \& Maas, A. 2010 b. High-level phylogenetic analysis using developmental sequences: The Cambrian $\uparrow$ Martinssonia elongata, $†$ Musacaris gerdgeyeri gen. et sp. nov. and their position in early crustacean evolution. Arthropod Structure \& Development 39, 154-173. DOI 10.1016/j.asd.2010.01.005

Haug, J.T., Waloszer, D., MaAs, A., Liu, Y. \& Haug, C. 2012. Functional morphology, ontogeny and evolution of mantis shrimp-like predators in the Cambrian. Palaeontology 55, 369-399. DOI 10.1111/j.1475-4983.2011.01124.x

Horner, J.R. \& Goodwin, M.B. 2009. Extreme cranial ontogeny in the Upper Cretaceous dinosaur Pachycephalosaurus. PLoS ONE 4(10), e7626. DOI 10.1371/journal.pone.0007626

Hörnig, M.K., Haug, C., Herd, K.J. \& Haug, J.T. 2014. New insights into dictyopteran early development: smallest Palaeozoic roachoid nymph found so far. Palaeodiversity 7 , 159-165.

Hörnig, M.K., Sombke, A., Haug, C., Harzsch, S. \& Haug, J.T. 
2016. What nymphal morphology can tell us about parental investment - a group of cockroach hatchlings in Baltic Amber documented by a multi-method approach. Palaeontologia Electronica 19(1), art. 5A, 1-20.

HYŽNÝ, M. \& KLOMPMAKER, A.A. 2015. Systematics, phylogeny, and taphonomy of ghost shrimps (Decapoda): a perspective from the fossil record. Arthropod Systematics \& Phylogeny 73(3), 401-437.

Maas, A., Waloszek, D., Haug, J.T. \& Müller, K.J. 2007. A possible larval round worm from the Cambrian 'Orsten' and its bearing on the phylogeny of Cycloneuralia. Memoirs of the Association of Australasian Palaeontologists 34, 499-519.

Maas, A., Waloszek, D., Haug, J.T. \& Müller, K.J. 2009. Loricate larvae (Scalidophora) from the Middle Cambrian of Australia. Memoirs of the Association of Australasian Palaeontologists 37, 281-302.

Minelli, A., Brena, C., Deflorian, G., Maruzzo, D. \& Fusco, G. 2006. From embryo to adult-beyond the conventional periodization of arthropod development. Development Genes \& Evolution 7-8, 373-383. DOI 10.1007/s00427-006-0075-6

Müller, C.H.G., Sombke, A. \& Rosenberg, J. 2007. The fine structure of the eyes of some bristly millipedes (Penicillata, Diplopoda: Additional support for the homology of mandibulate ommatidia. Arthropod Structure \& Development 36(4), 463-476. DOI 10.1016/j.asd.2007.09.002

Nguyen Duy-JacQuemin, M. 2006. Condexenus, a new genus of the millipede family Synxenidae (Diplopoda, Polyxenida) from Namibia. Norwegian Journal of Entomology 53, $237-248$.

Nguyen Duy-Jacquemin, M. \& Azar, D. 2004. The oldest records of Polyxenida (Myriapoda, Diplopoda): new discoveries from the Cretaceous ambers of Lebanon and France. Geodiversitas 26(4), 631-641.

Nguyen Duy-Jacquemin, M., Uys, C. \& Geoffroy, J.J. 2011. Two remarkable new species of Penicillata (Diplopoda, Polyxenida) from Table Mountain National Park (Cape Town, South Africa). In Mesibov, R. \& Short, M. (eds) Proceedings of the $15^{\text {th }}$ International Congress of Myriapodology, 18-22 July 2011, Brisbane, Australia. ZooKeys 156, 85-103. DOI 10.3897/zookeys.156.2211

NüTZEL, A. 2014. Larval ecology and morphology in fossil gastropods. Palaeontology 57(3), 479-503.

DOI 10.1111/pala.12104

Nützel, A., Frýda, J., Yancey, T.E. \& Anderson, J.R. 2007.
Larval shells of Late Palaeozoic naticopsid gastropods (Neritopsoidea: Neritimorpha) with a discussion of the early neritimorph evolution. Paläontologische Zeitschrift 81, 213-228.

Rasnitsyn, A.P. \& Golovatch, S.I. 2004. The identity of Phryssonotus burmiticus (Cockerell, 1917) (Diplopoda, Polyxenida, Synxenidae) in Cretaceous amber from Myanmar. Journal of Systematic Palaeontology 2(2), 153-157. DOI 10.1017/S1477201904001233

Scannella, J.B. \& HoRner, J.R. 2010. Torosaurus Marsh, 1891, is Triceratops Marsh, 1889 (Ceratopsidae: Chasmosaurinae): synonymy through ontogeny. Journal of Vertebrate Paleontology 30(4), 1157-1168. DOI 10.1080/02724634.2010.483632

SheAR, W.A. 2011. Class Diplopoda de Blainville in Gervais, 1844, 159-164. In ZhANG, Z.Q. (ed.) Animal biodiversity: An outline of higher-level classification and survey of taxonomic richness. Zootaxa 3148.

Shear, W.A. \& Edgecombe, G.D. 2010. The geological record and phylogeny of the Myriapoda. Arthropod Structure \& Development 39, 174-190. DOI 10.1016/j.asd.2009.11.002

Short, M. \& Huynh, C. 2006. Redescription of Phryssonotus novaehollandiae (Silvestri, 1923) with details of post-embryonic stadia. Norwegian Journal of Entomology 53, 211-222.

Short, M. \& Huynh, C. 2009. Phryssonotus novaehollandiae Silvestri, 1923: the sole Australian representative of the millipede Family Synxenidae. Soil Organisms 81, 695-700.

Short, M. \& HuYnh, C. 2010. Revision of the genus Propolyxenus Silvestri with description of a new species. International Journal of Myriapodology 3, 1-17. DOI 10.1163/187525410X12578602960263

Simonetta, A.M. \& Delle Cave, L. 1981. An essay in the comparative and evolutionary morphology of Palaeozoic arthropods. Origine dei Grandi Phyla dei Metazoi, Atti die Convegni Lincei 49, 389-439.

Wehner, R. \& Gehring, W.J. 2013. Zoologie. 792 pp. Georg Thieme Verlag, Stuttgart. DOI 10.1055/b-002-99143

Weitschat, W. \& WichaRD, W. 2002. Atlas of plants and animals in Baltic amber. 256 pp. Dr. Friedrich Pfeil. München.

Wolfe, A.P., McKellar, R.C., Tappert, R., Sodhi, R.N. \& MueHLEnBACHs, K. 2016. Bitterfeld amber is not Baltic amber: Three geochemical tests and further constraints on the botanical affinities of succinite. Review of Palaeobotany and Palynology 225, 21-32. DOI 10.1016/j.revpalbo.2015.11.002 